\title{
Map-based cloning and promoter variation analysis of the lobed leaf gene BoLMI1a in ornamental kale (Brassica oleracea L. var. acephala)
}

Bin Zhang ${ }^{\dagger}$, Wendi Chen ${ }^{\dagger}$, Xing Li ${ }^{\dagger}$, Wenjing Ren, Li Chen, Fengqing Han, Zhiyuan Fang, Limei Yang, Mu Zhuang, Honghao Lv, Yong Wang and Yangyong Zhang*

\begin{abstract}
Background: Leaf shape is an important agronomic trait in ornamental kale (Brassica oleracea L. var. acephala). Although some leaf shape-related genes have been reported in ornamental kale, the detailed mechanism underlying leaf shape formation is still unclear. Here, we report a lobed-leaf trait in ornamental kale, aiming to analyze its inheritance and identify the strong candidate gene.

Results: Genetic analysis of $\mathrm{F}_{2}$ and $\mathrm{BC}_{1}$ populations demonstrate that the lobed-leaf trait in ornamental kale is controlled by a single dominant gene, termed BoLl-1 (Brassica oleracea lobed-leaf). By performing whole-genome resequencing and linkage analyses, the BoLl-1 gene was finely mapped to a 127-kb interval on chromosome C09 flanked by SNP markers SL4 and SL6, with genetic distances of $0.6 \mathrm{cM}$ and $0.6 \mathrm{cM}$, respectively. Based on annotations of the genes within this interval, Bo9g181710, an orthologous gene of LATE MERISTEM IDENTITY 1 (LMI1) in Arabidopsis, was predicted as the candidate for BoLI-1, and was renamed BoLMI1a. The expression level of BoLMI1a in lobed-leaf parent 18Q2513 was significantly higher compared with unlobed-leaf parent 18Q2515. Sequence analysis of the parental alleles revealed no sequence variations in the coding sequence of BoLMI1a, whereas a 1737-bp deletion, a 92-bp insertion and an SNP were identified within the BoLMI1 a promoter region of parent 18Q2513. Verification analyses with BoLMI1a-specific markers corresponding to the promoter variations revealed that the variations were present only in the lobed-leaf ornamental kale inbred lines.

Conclusions: This study identified a lobed-leaf gene BoLMI1a, which was fine-mapped to a 127-kb fragment. Three variations were identified in the promoter region of BoLMI1a. The transcription level of BoLMI1 a between the two parents exhibited great difference, providing new insight into the molecular mechanism underlying leaf shape formation in ornamental kale.
\end{abstract}

Keywords: Ornamental kale, Lobed leaf, Fine mapping, Promoter variation, Enhanced expression

\footnotetext{
*Correspondence: zhangyangyong@caas.cn

${ }^{\dagger}$ Bin Zhang, Wendi Chen and Xing Li contributed equally to this work. Key Laboratory of Biology and Genetic Improvement of Horticultural Crops, Ministry of Agriculture, Institute of Vegetables and Flowers, Chinese Academy of Agricultural Sciences, \#12 Zhong Guan Cun Nandajie Street, Beijing 100081, China
} original author(s) and the source, provide a link to the Creative Commons licence, and indicate if changes were made. The images or other third party material in this article are included in the article's Creative Commons licence, unless indicated otherwise in a credit line to the material. If material is not included in the article's Creative Commons licence and your intended use is not permitted by statutory regulation or exceeds the permitted use, you will need to obtain permission directly from the copyright holder. To view a copy of this licence, visit http://creativecommons.org/licenses/by/4.0/. The Creative Commons Public Domain Dedication waiver (http://creativeco mmons.org/publicdomain/zero/1.0/) applies to the data made available in this article, unless otherwise stated in a credit line to the data. 


\section{Background}

Leaves are essential organs that play an important role in plants, including carbon assimilation, gas exchange, water transport and nutrient distribution [1]. Leaf shape can significantly affect both leaf function and plant architecture [2, 3]. A typical variation in leaf shape involves the leaf margin, which can be unlobed, serrated or lobed [4]. Lobed leaves can be easily visualized even in the primary leaf stage, which can be used as an indicator trait for hybrid production $[5,6]$. Compared to unlobed- or serrated-leaf lines, plants with lobed leaves are better adapted to environmental stresses [7, 8]. With improved heat transfer and light energy absorption, lobed leaves are advantageous for high-density planting and mechanized production [9]. Additionally, lobed leaves are also a graceful decorative trait for ornamental plants such as kale [4].

Ornamental kale (Brassica oleracea L. var. acephala) is an attractive ornamental crop owing to its polymorphic, colorful leaves [10]. Lobed-leaf genes have been genetically analyzed and mapped in some Brassica species. For example, the lobed-leaf trait in $B$. rapa is controlled by major gene or polygenic effects [11-14]. In $B$. napus, the incomplete dominant lobed-leaf gene $B n L L 1$ was mapped to the distal end of chromosome A10 [15]. In ornamental kale, some studies have shown that the lobed-leaf trait exhibits incomplete dominance over the unlobed-leaf trait [16]. Genetic analysis of an interspecific hybrid between B. napus and Rorippa indica (L.) Hiern revealed that the lobed-leaf trait is controlled by a dominant gene [9]. Moreover, Ren et al. mapped a quantitative trait locus (QTL) associated with lobed leaves to chromosome 9 of ornamental kale flanked by insertion-deletion (InDel) markers LYIn39 and LYIn40, with genetic distances of $0.17 \mathrm{cM}$ and $0.11 \mathrm{cM}$, respectively [4].

With the development of high-throughput sequencing technology and the release of $B$. oleracea draft genomes [17, 18], a growing number of genes that govern important traits have been mapped in this species. Bulk segregant analysis (BSA) is a rapid and accurate gene mapping method that was first developed and performed in plants [19]. This method is characterized by bulk genotyping of a pool of segregants that share the same phenotype. InDel has been considered as an ideal source for marker design due to its high-density distribution and genotyping efficiency. Using InDel markers, many genes/QTLs have been mapped in $B$. oleracea, including the yellow-green leaf gene $y g l-1$ [20], the purple leaf gene $B o P r$ [21], QTLs associated with heading traits [22], male sterility genes [23, 24] and the petal color gene BoCCD4 [25].

Lobed-leaf trait is a unique variation in kale that can be produced by infrequent genetic mechanisms. In the present study, we developed $F_{1}, F_{2}$ and $B_{1}$ populations descended from the ornamental kale inbred line 18Q2513 (with lobed leaves) and 18Q2515 (with unlobed leaves). A rare dominant inheritance pattern was identified for lobed-leaf trait using these populations. Furthermore, the lobed-leaf gene BoLl-1 was fine-mapped to a narrow interval using BSA-seq and linkage analysis. The findings provide new insight into the molecular mechanism underlying leaf shape formation in ornamental kale.

\section{Results}

\section{Genetic analysis of leaf shape in ornamental kale}

The leaf shape throughout all the $\mathrm{F}_{1}$ plants (comprising 16 individuals) generated by crossing 18Q2513 (lobedleaf, Fig. 1a) with 18Q2515 (unlobed-leaf, Fig. 1b) was lobed; thus, the lobed-leaf trait is dominant over the unlobed-leaf trait in these two ornamental kale lines. The $\mathrm{F}_{2}$ population comprised 120 individuals, with 92 displaying lobed leaves and 28 unlobed leaves. According to a chi-square test, the segregation ratio is $3: 1$. The $\mathrm{BC}_{1} \mathrm{P}_{1}$ population contained 850 individuals, with 429 lobed-leaf individuals and 421 unlobed-leaf individuals,

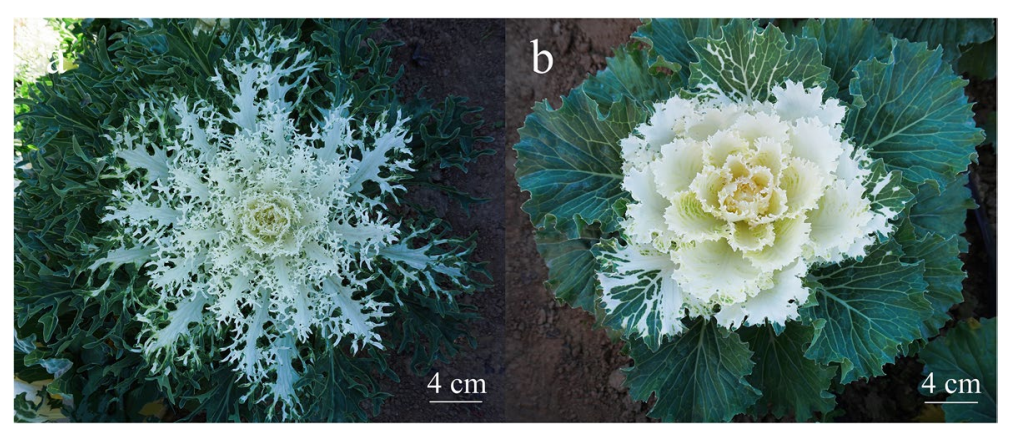

Fig. 1 Leaf phenotypes of the parental lines. a 18Q2513 with lobed leaves. b $18 Q 2515$ with unlobed leaves. Bar $=4 \mathrm{~cm}$ 
Table 1 The Chi-square $\left(x^{2}\right)$ goodness-of-fit test ratios of leaf shape segregation in $B C$ and $F_{2}$ populations

\begin{tabular}{llllll}
\hline Populations & $\begin{array}{l}\text { Total } \\
\text { plant } \\
\text { number }\end{array}$ & $\begin{array}{l}\text { Number of } \\
\text { lobed-leaf } \\
\text { individuals* }\end{array}$ & $\begin{array}{l}\text { Number of } \\
\text { unlobed- } \\
\text { leaf } \\
\text { individuals* }\end{array}$ & $\begin{array}{l}\text { Expected } \\
\text { ratio }\end{array}$ & $\mathrm{x}^{2 \mathrm{a}}$ \\
\hline $\mathrm{F}_{1}$ & 16 & 16 & 0 & - & - \\
$\mathrm{F}_{2}$ & 120 & 92 & 28 & $3: 1$ & 0.18 \\
$\mathrm{BC}_{1} \mathrm{P}_{1}$ & 850 & 429 & 421 & $1: 1$ & 0.08 \\
$\mathrm{BC}_{1} \mathrm{P}_{2}$ & 200 & 200 & 0 & - & - \\
\hline
\end{tabular}

${ }^{a} X^{2}>X_{0.05}^{2}=3.84$ was considered significant

*Lobed-leaf plants and unlobed-leaf plants were determined at the seedling stage by visual inspection

and the segregation ratio was confirmed to be $1: 1$ by a chi-square test. The $200 \mathrm{BC}_{1} \mathrm{P}_{2}$ individuals all had lobed leaves (Table 1). These results indicate that the lobedleaf trait is controlled by a single dominant gene, which was named $B o L l-1$.

\section{Fine mapping of the BoLI-1 gene by BSA-seq and linkage analyses}

To identify markers associated with lobed leaves, the SNP index and $\Delta$ (SNP index) between the two bulks were calculated using high-quality SNPs. The average SNPindex and $\Delta$ (SNP-index) of the two bulks across a $1-\mathrm{Mb}$ genomic interval were measured using a 10-kb sliding window and plotted against the genome position. The highest peak region, which was considered to be the candidate interval associated with BoLl-1, contains approximately $1.33 \mathrm{Mb}(53.34-54.67 \mathrm{Mb})$ on chromosome 9 according to the 'TO1000' reference genome (Fig. 2a). For the candidate region of BoLl-1, 3280 SNPs between parental lines were identified, 410 of which are effective; 593 InDels were identified, 35 of which are effective (Table S1).

To further delineate the location of BoLl-1, 16 InDel and seven SNP markers (by comparing resequencing data of the parents with the sequence of the TO1000 reference genome) within the $1.33-\mathrm{Mb}$ candidate region and its flanking regions $(600 \mathrm{~kb}$ on each side) were designed. Ultimately, five InDel and three SNP markers showed polymorphisms between the two parents. A total of 429 recessive individuals of the $B C_{1} P_{1}$ population were subsequently used for BoLl-1 fine mapping.

A linkage map consisting of five InDel and three SNP markers was constructed using MapDraw (Fig. 2b). The SNP markers SL4 and SL6 were found to be tightly linked to $\mathrm{BoLl}-1$, with genetic distances of $0.6 \mathrm{cM}$ and $0.6 \mathrm{cM}$, respectively. Based on the marker locations in the reference genome, BoLl-1 was ultimately delimited to a $127-\mathrm{kb}$ region $(53680797-53,808,289 \mathrm{bp})$ on chromosome C09.
Prediction and expression analysis of the candidate genes Based on the 'TO1000' reference genome [18], 21 genes were identified within the 127-kb interval (Table 2). According to annotations from the Brassica oleracea genome and BLASTX (best hit) to A. thaliana, only two genes Bo $9 g 181710$ and $B o 9 g 181720$ are related to the formation of leaf shape. These two genes are homologues of the LATE MERISTEM IDENTITY 1 (LMI1) gene in Arabidopsis, which encode a homeodomain leucine zipper class I (HD-Zip I) meristem identity regulator that plays an important role in leaf morphogenesis and bract formation. Thus, we designated that Bo9g181710 and Bo9g181720 were candidate genes controlling lobed leaf shape in ornamental kale.

To analyze the expression patterns of $B o 9 g 181710$ and Bo $9 g 181720$, qRT-PCR was performed using young leaves from 28-day-old seedling of the parents. The expression level of Bo9g181710 in lobed-leaf 18Q2513 was significantly higher than that in unlobed-leaf $18 \mathrm{Q} 2515$, whereas no significant difference in Bo9g181720 expression between the parental lines was detected (Fig. 3).

\section{Sequence analysis of the candidate genes}

To determine the causal relationship between the candidate genes and leaf shape formation, a comparative sequence analysis of the Bogg181710 and Bo9g181720 genes body (DNA) and $\sim 3-\mathrm{kb}$ promoter region was performed using genomic DNA from 18Q2513 and 18Q2515. No sequence variations (between the parental lines) in the coding sequences of Bo9g181710 were detected, while a 1737-bp deletion (1466 bp upstream of the transcription start site), a 92-bp insertion (1466bp upstream of the transcription start site) and an SNP (765 bp upstream of the transcription start site) were identified within the Bo9g181710 promoter region of 18Q2513 (Fig. 4a). Conversely, no variation was detected in either the promoter or coding regions of Bo9g181720 between the 18Q2513 and 18Q2515. Combined with expression analysis, we speculated that the Bogg181710 may control the formation of leaf shape in ornamental kale, and renamed it BoLMI1a. In addition, we renamed the Bogg181720 to BoLMI1b.

Sequence analysis further revealed that BoLMI1a, which consists of three exons and two introns, encodes a putative 219-amino acid protein containing a homeobox domain and a leucine zipper domain (Fig. 4). Sequence alignment of the BoLMIIa and BoLMIIb proteins and its seven homologues from other cruciferous species revealed that BoLMIIa shared a high degree of similarity with its homologues in B. napus (98.17\%) and $B$. rapa $(91.32 \%)$ but a relatively lower degree of similarity with BoLMIIb (59.41\%) and Camelina sativa (54.92\%) (Fig. 4b). Furthermore, a phylogenetic analysis of the 


\section{a}

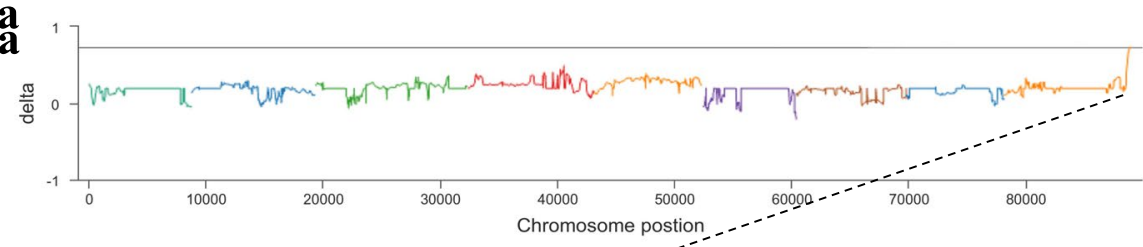

b

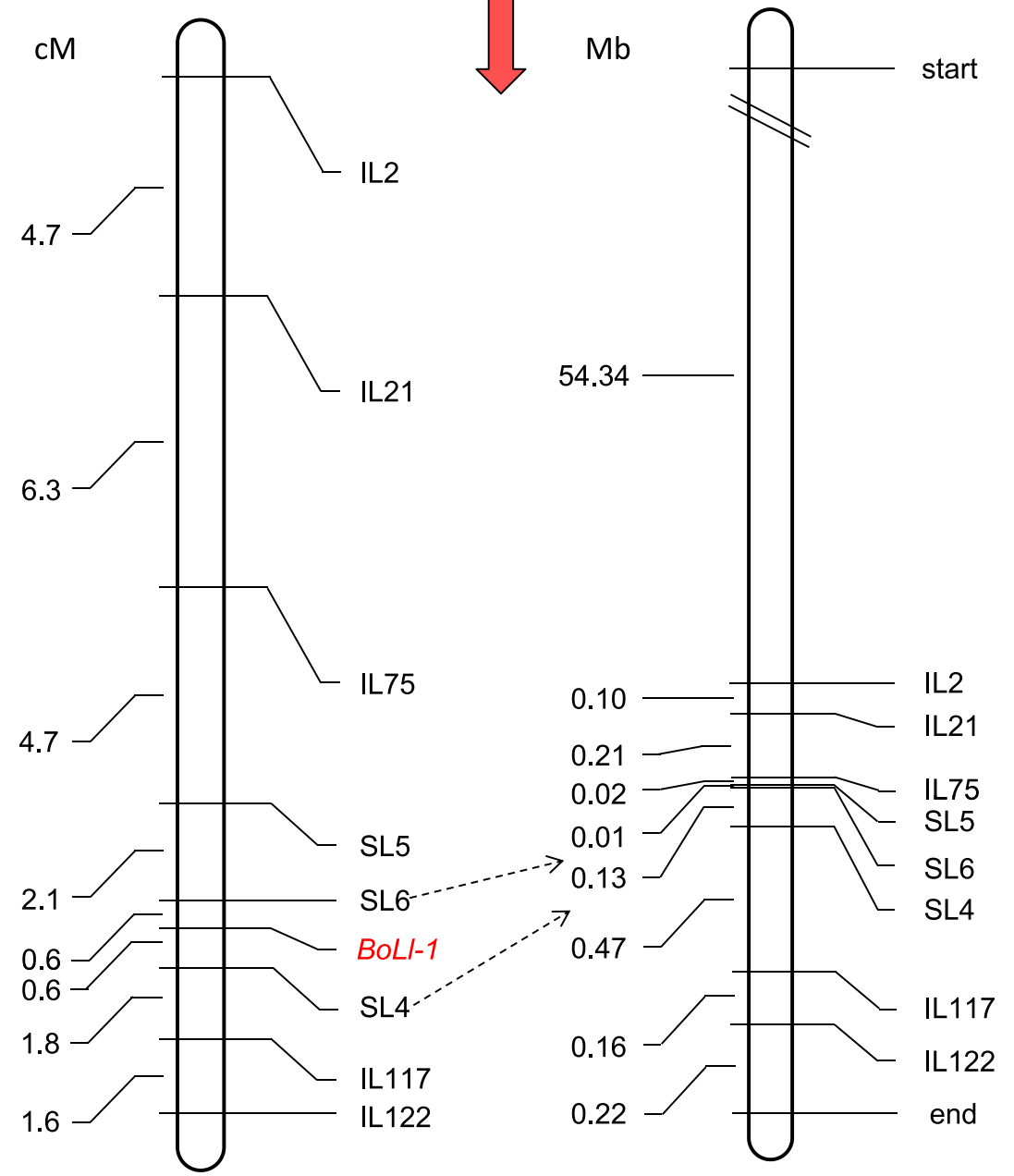

Fig. 2 Fine mapping of the BoLl-1 gene in ornamental kale. a Plot of the $\triangle$ (SNP-index) value obtained from the two bulks. The top line indicates the threshold line. The $x$-axis represents the position of nine chromosomes and the $y$-axis represents the $\triangle(S N P$-index). $\mathbf{b}$ Linkage map of the BoLI- 1 . The left panel is a genetic map of BoLl-1 in the target region (units: CM). The right panel is the corresponding physical map of BoLl-1 (units: Mb)

BoLMIIa and BoLMI1b proteins and its close homologues was carried out to evaluate their evolutionary relatedness. The results showed that BoLMI1a is closely related to $B$. napus $A T H B-51$ and is located in the same clade as other cruciferous plants, indicating that they may be derived from the same ancestor gene (Fig. 5).

\section{Verification of BoLMI1a-specific markers}

Using the co-dominant marker CMLMI1 and the dCAPS marker DMLMI1, we determined whether the variations the BoLMI1a promoter are also present in 118 different cabbage inbred lines (with unlobed leaves) and another ornamental kale inbred line 18Q2523 (with lobed leaves). The results indicated that the insertion, deletion (detected by co-dominant marker CMLMI1) and the SNP (detected by dCAPS marker DMLMI1) were present only in the lobed-leaf ornamental kale inbred line 18Q2523 (Fig. 6; Fig. S1). These markers exhibited 100\% accuracy which can be used for marker-assisted selection. Overall, the analyses strongly indicated that the variations in 
Table 2 The 21 putative gene models in the target mapping region

\begin{tabular}{|c|c|c|c|}
\hline Gene ID & Location & $\begin{array}{l}\text { Homologous } \\
\text { gene in } A . \\
\text { thaliana }\end{array}$ & Annotation \\
\hline Bo9g181620 & C9: $53678143-53,680,993$ & AT5G03900 & iron-sulphur cluster biosynthesis family protein \\
\hline Bo9g181630 & C9: $53681760-53,682,275$ & AT5G03890 & hypothetical protein \\
\hline Bo9g181640 & C9: $53685355-53,687,538$ & AT5G03880 & thioredoxin family protein \\
\hline Bo9g181650 & C9: 53697594-53,698,572 & - & - \\
\hline Bo9g181660 & C9: 53698893-53,699,987 & AT5G03850 & nucleic acid-binding, OB-fold-like protein \\
\hline Bo9g181670 & C9: $53703655-53,704,734$ & AT5G03840 & protein TERMINAL FLOWER 1 \\
\hline Bo9g181680 & C9: $53711576-53,712,658$ & - & - \\
\hline Bo9g181690 & C9: 53713320-53,715,156 & AT5G03795 & probable glycosyltransferase \\
\hline Bo9g181700 & C9: $53717227-53,718,573$ & AT5G03795 & probable glycosyltransferase \\
\hline Bo9g181710 & C9: $53720142-53,721,856$ & AT5G03790 & encodes a homeodomain leucine zipper class I (HD-Zip I) meristem identity regulator \\
\hline Bo9g181720 & C9: 53749509-53,750,894 & AT5G03790 & encodes a homeodomain leucine zipper class I (HD-Zip I) meristem identity regulator \\
\hline Bo9g181730 & C9: $53755444-53,758,253$ & AT5G03770 & probable 3-deoxy-D-manno-octulosonic acid transferase \\
\hline Bo9g181740 & C9: 53760949-53,762,178 & - & - \\
\hline Bo9g181750 & C9: $53765687-53,769,942$ & AT5G03760 & glucomannan 4-beta-mannosyltransferase 9 \\
\hline Bo9g181760 & C9: 53771597-53,773,283 & AT5G03740 & histone deacetylase $2 \mathrm{C}$ \\
\hline Bo9g181770 & C9: $53777463-53,782,597$ & AT5G03730 & serine/threonine-protein kinase CTR1 \\
\hline Bo9g181780 & C9: 53783895-53,785,735 & AT5G03720 & heat shock transcription factor A3 \\
\hline Bo9g181790 & C9: 53793205-53,794,037 & - & - \\
\hline Bo9g181800 & C9: $53801111-53,802,559$ & AT5G03700 & D-mannose binding lectin protein with Apple-like carbohydrate-binding domain \\
\hline Bo9g181810 & C9: $53803210-53,804,612$ & AT5G03690 & fructose-bisphosphate aldolase 4 \\
\hline Bo9g181820 & C9: $53807596-53,810,446$ & AT5G03680 & trihelix transcription factor PTL \\
\hline
\end{tabular}

the promoter of BoLMI1a exist only in lobed-leaf ornamental kale inbred lines and may be responsible for the change in leaf shape from unlobed to lobed.

\section{Discussion}

In previous studies, the lobed-leaf trait was reported to be controlled by an incomplete gene or a QTL in ornamental kale $[4,16,26]$. In the present study, we analyzed the inheritance of leaf shape using $\mathrm{F}_{2}$ and $\mathrm{BC}$ populations derived from a cross of lobed-leaf ornamental kale with unlobed-leaf ornamental kale, showing that the lobedleaf trait is controlled by a single dominant nuclearencoded gene.

Ren et al. mapped the lobed-leaf gene BoLl to chromosome 9 of ornamental kale flanked by InDel markers LYIn39 and LYIn40, with genetic distances of $0.17 \mathrm{cM}$ and $0.11 \mathrm{cM}$, respectively [4]. Two candidate genes, Bol010029/Bo9g181710 and Bol010030/Bo9g1181720, were revealed, but no sequence variations were found in their promoter and coding regions according to the B. oleracea '0212' (cabbage) [17] and 'TO1000' (Chinese kale like) genomes [18]. Therefore, the authors did not conclude which gene controlled the formation of leaf shape in ornamental kale. In our study, based on the 'TO1000' genome, the $B o L l-1$ gene was finely mapped to a 127 kb $(53680797-53,808,289 \mathrm{bp})$ interval on chromosome 9. SNP markers SL4 and SL6 were tightly linked to $B o L l-1$, flanking the gene at genetic distances of $0.6 \mathrm{cM}$ and $0.6 \mathrm{cM}$, respectively. Sequence analysis of the parental alleles revealed no sequence variations in the coding sequence of $B o 9 g 181710$, whereas three variations were identified in the promoter region. In contrast, no sequence variations were detected in the promoter and coding regions of $B o 9 g 181720$. The expression level of Bo9g181710 in lobed-leaf 18Q2513 was significantly higher compared with unlobed-leaf 18Q2515, though the expression level of Bo9g181720 was similar between the parental lines. Thus, we further confirmed that the Bo9g181710 may control the formation of leaf shape in ornamental kale.

In B. napus, $\mathrm{Hu}$ et al. reported that a 2624-bp insertion (317 bp upstream of the transcription start site) and three SNPs were identified in the BnA10.LMII promoter sequence, along with 12 SNPs in the $3^{\prime}$ flanking sequence, which were considered to be the cause of the lobed-leaf formation [27]. In ornamental kale, the genes that determine leaf shape are not fully understood. Ren et al. mapped the BoLl gene and found no sequence variations in the promoter and coding regions 


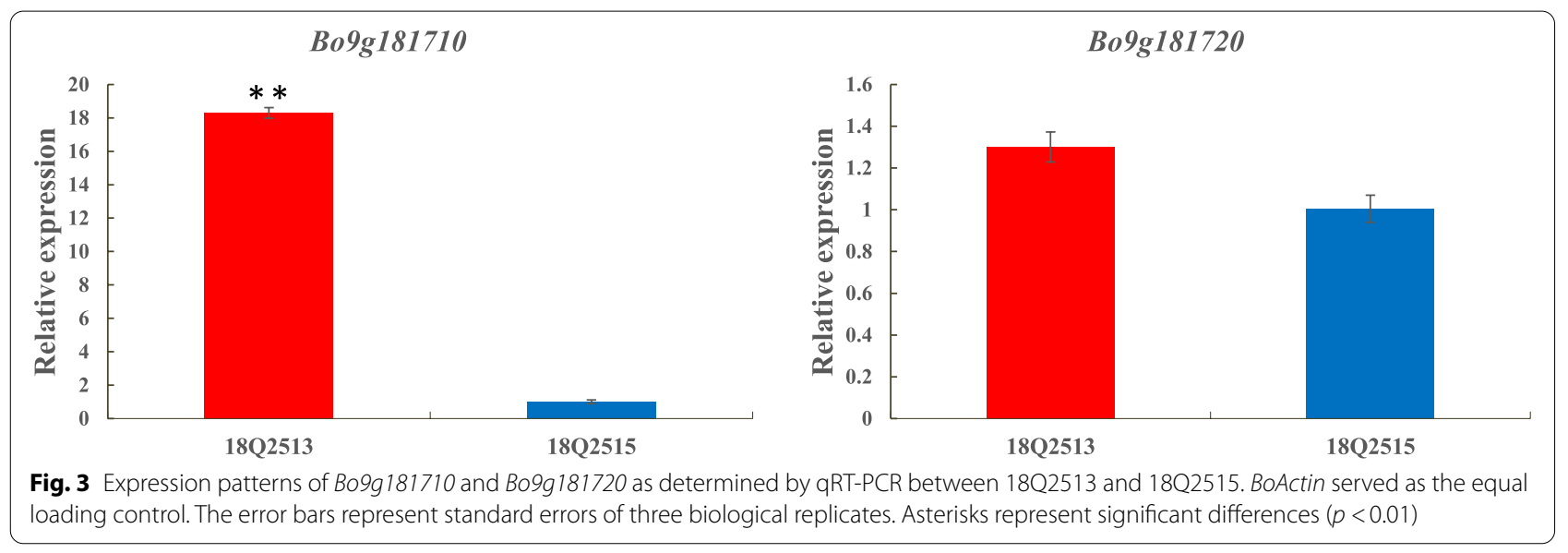

of candidate [4]. In our study, three variations, including an SNP, a 1737-bp deletion, and a 92-bp insertion (765 bp, $1466 \mathrm{bp}$, and $1466 \mathrm{bp}$ upstream of the transcription start site, respectively) were identified in the BoLMI1 a promoter region compared with the 'TO1000' reference genome. Through verification analyses of
BoLMI1a-specific markers corresponding to the promoter variations revealed that the variations existed only in lobed-leaf ornamental kale inbred lines. These variations may strongly enhance the transcription levels of BoLMI1, thus changing leaf shape from unlobed to lobed.

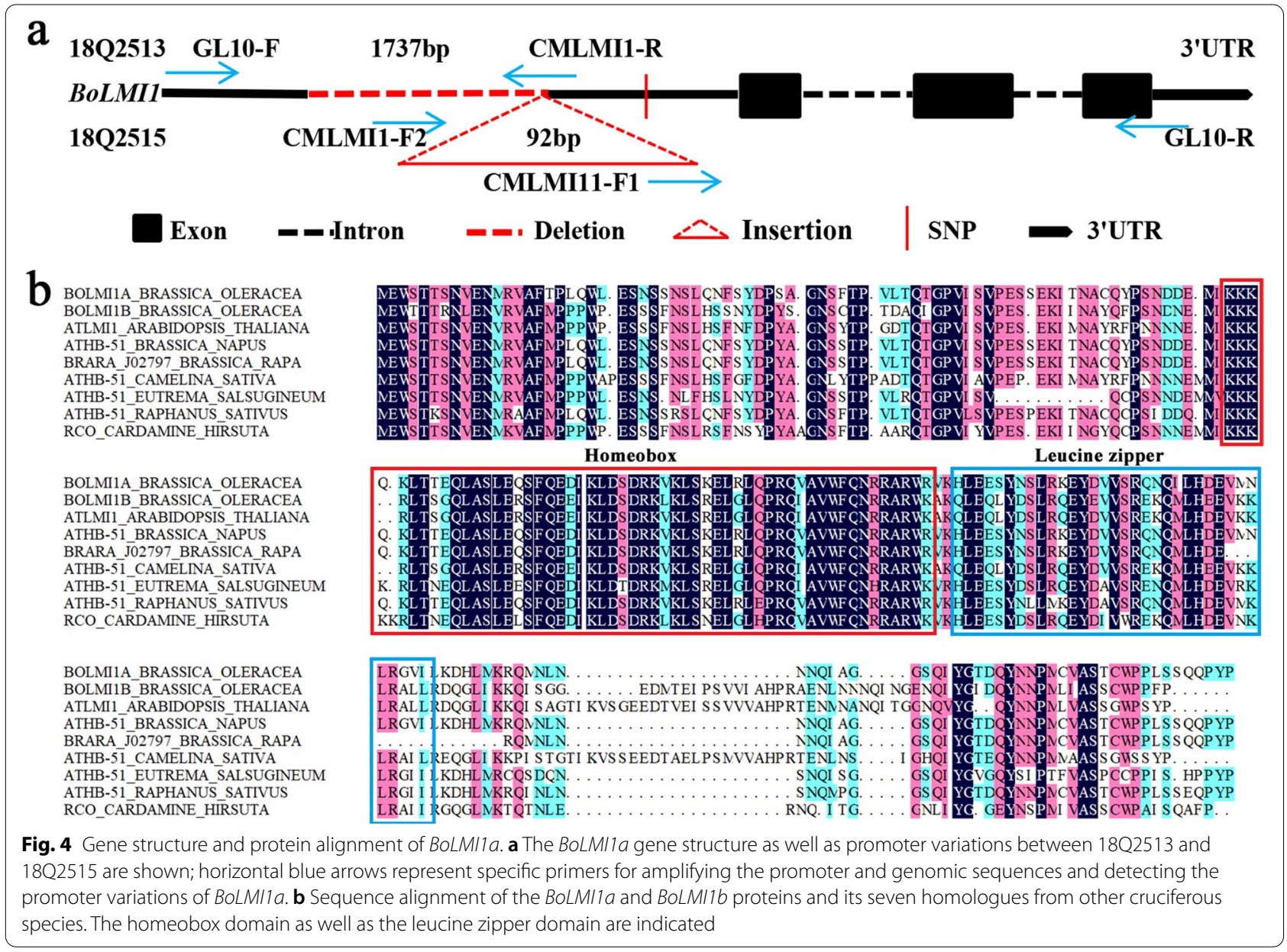




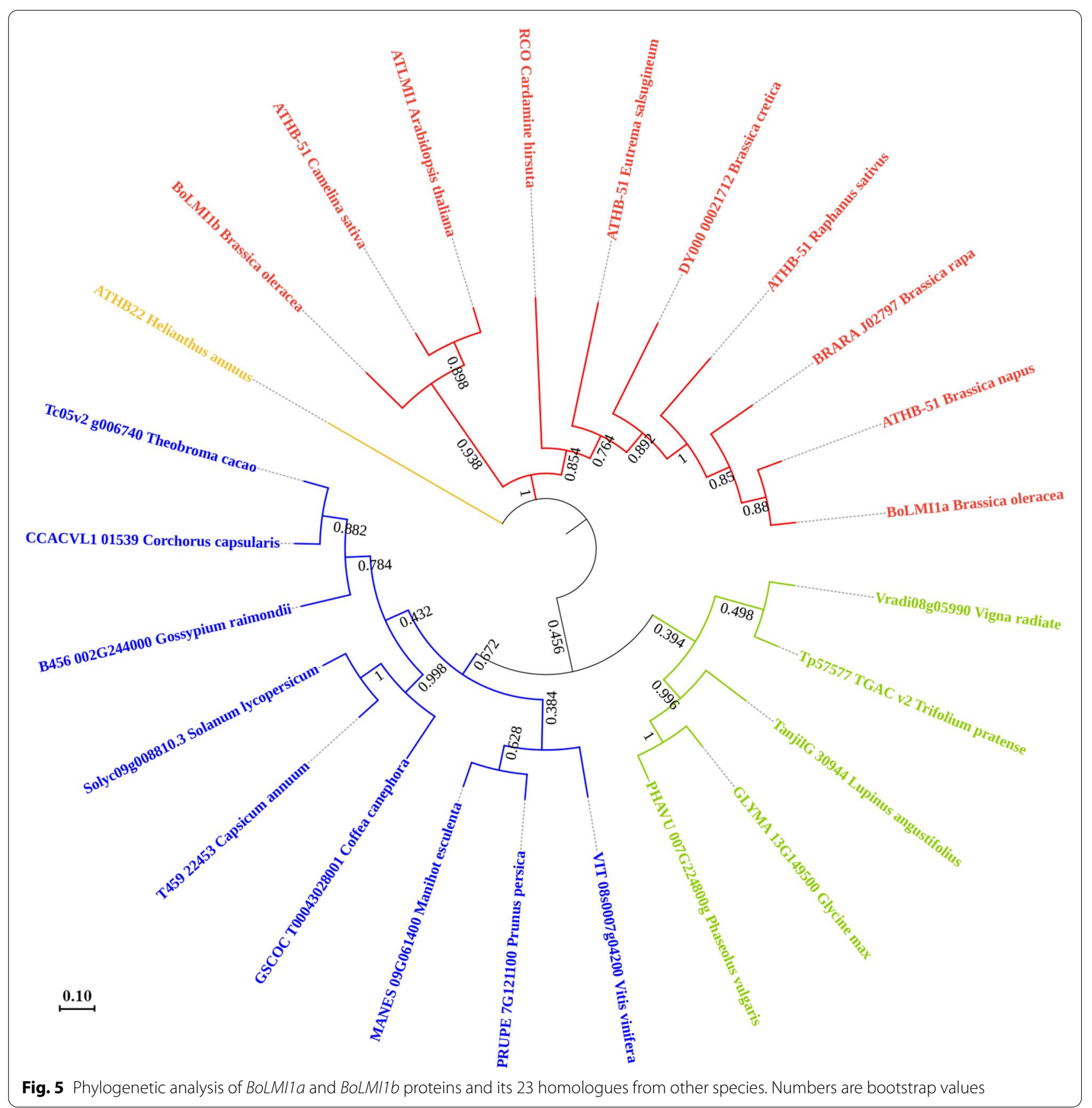

Leaf shape plays an important role in the reproduction and evolution of plants. Increasing evidence indicates that lobed leaves can improve photosynthesis efficiency and agronomic profitability [7, 28-31]. LMI1-like genes encoding an HD-Zip I transcription factor have been functionally identified in several plants, and they were reportedly involved in leaf shape formation [27, 32-35]. For example, $\mathrm{Hu}$ et al. [27] identified the BnA10.LMI1 gene, which was responsible for the lobed-leaf shape in
Brassica napus. In addition, the BnA10.LMI1 knockout mutations in the HY (with lobed leaves) background were sufficient to produce unlobed leaves. In this study, we identified an LMI1-like gene, BoLMI1a, which was the strong candidate gene underlying the lobed-leaf trait in ornamental kale. Thus, our findings further strengthen the potential for revealing the molecular mechanism underlying leaf shape formation, and we showed that BoLMI1a-specific markers (CMLMI1 and DMLMI1) can 


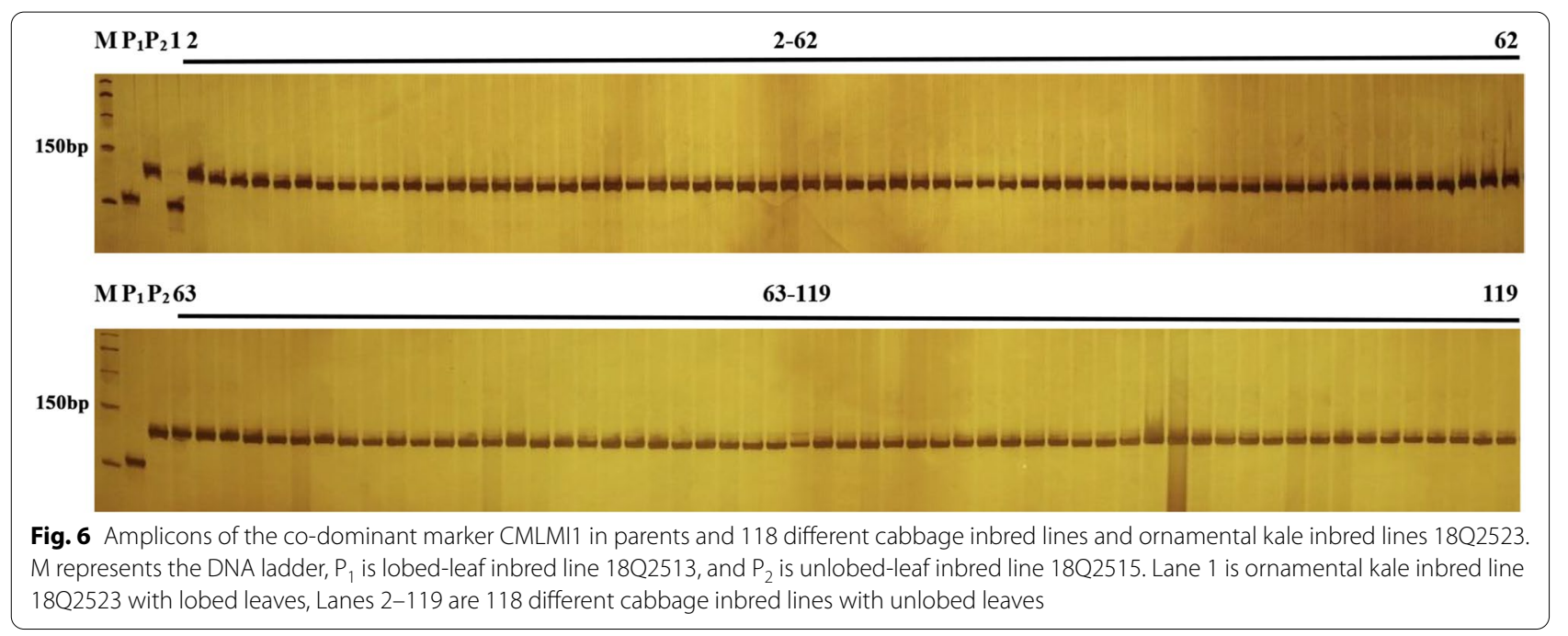

be used for marker-assisted selection in ornamental kale breeding.

\section{Conclusions}

In this study, the lobed-leaf trait is shown to be controlled by a single dominant gene, BoLl-1, in ornamental kale. The $B o L l-1$ gene was fine-mapped to a $127-\mathrm{kb}$ fragment. A homologue of Arabidopsis LMI1, BoLMI1a was identified as a strong candidate gene. Three variations were identified in the promoter region of BoLMI1a. The expression of BoLMI1a in lobed-leaf parent 18Q2513 was significantly up-regulated compared with unlobed-leaf parent $18 \mathrm{Q} 2515$. This study lays a foundation for cloning BoLMI1 $a$ and provides new insight into the formation of leaf shape in ornamental kale.

\section{Methods}

\section{Plant materials}

The 18Q2513 female parent $\left(\mathrm{P}_{1}\right)$ is an ornamental kale inbred line with lobed leaves; the 18Q2515 male parent $\left(\mathrm{P}_{2}\right)$ is an ornamental kale inbred line with unlobed leaves. 18Q2513 was crossed with 18Q2515 to generate an $F_{1}$ population. An $F_{2}$ population was generated from self-pollination of the $\mathrm{F}_{1}$ plants; $\mathrm{BC}_{1} \mathrm{P}_{1}$ and $\mathrm{BC}_{1} \mathrm{P}_{2}$ were then generated by BCs of $\mathrm{F}_{1} \times 18 \mathrm{Q} 2513, \mathrm{~F}_{1} \times 18 \mathrm{Q} 2515$, respectively.

Additionally, 118 different cabbage inbred lines (with unlobed leaves) and another ornamental kale inbred line 18Q2523 (with lobed leaves), were screened for BoLl-1 promoter variations. All of the plant materials used in the present study were grown in a $25^{\circ} \mathrm{C} \pm 2{ }^{\circ} \mathrm{C}$ greenhouse (16 h light $/ 8 \mathrm{~h}$ dark photoperiod) at the seedling stage and then transplanted to the field after 1 month. Daily watering and fertilization were performed regularly until the plants enter the flowering stage (about 3 months of vernalization from December to February of the next year). All the plant materials are from the Institute of Vegetables and Flowers, Chinese Academy of Agriculture Sciences (IVFCAAS, Beijing, China).

\section{Genetic analysis and whole-genome resequencing}

Leaf shape was investigated visually. Segregation ratios for the $\mathrm{F}_{2}$ and $\mathrm{BC}_{1}$ populations were analyzed by chisquare $\left(\chi^{2}\right)$ tests using SAS software.

Fifty lobed-leaf $\mathrm{BC}_{1}$ and fifty unlobed-leaf $\mathrm{BC}_{1}$ individuals were selected to construct two bulks. Genomic DNAs were isolated from the individuals within the two bulks and two parental lines using the Plant Genomic DNA Kit (Tiangen, Beijing, China), following the manufacturer's instructions. The quality of the DNAs was ensured using spectrophotometric analysis and agarose gel electrophoresis. Equally high-quality genomic DNAs from the two bulks and two parental lines were then used to construct paired-end sequencing libraries, which were subsequently sequenced with an Illumina $\mathrm{Hi}-\mathrm{Seq}$ 2500 sequencer by the Beijing Genomics Institute (BGI) (Shenzhen, China). SNP-index and sliding-window analyses were performed as previously described [36].

\section{Marker development and fine mapping of the BoLl-1 gene} InDel and SNP markers were designed based on candidate region resequencing data for the two parents. Markers were designed with amplicon lengths of $100-180 \mathrm{bp}$, GC contents of $40-50 \%$ and $\mathrm{Tm}$ values of $52-58^{\circ} \mathrm{C}$. The markers that were polymorphic between the parents were then used to analyze unlobed-leaf individuals in the $\mathrm{BC}_{1} \mathrm{P}_{1}$ populations. 
Genomic DNA was extracted from 28-day-old seedling young leaves of the parents and $\mathrm{BC}_{1} \mathrm{P}_{1}$ individuals using a modified cetyltrimethylammonium bromide (CTAB) protocol [37]. The DNA concentration was subsequently determined using a spectrophotometer (BioDrop, UK) and adjusted to $40-50 \mathrm{ng} / \mu \mathrm{L}$.

The $10-\mu \mathrm{L}$ PCR reaction mixture consisted of $2 \mu \mathrm{L}$ DNA template, $1 \mu \mathrm{L} 10 \times$ PCR buffer $\left(\mathrm{Mg}^{2+}\right.$ included), $0.8 \mu \mathrm{L}$ dNTPs $(2.5 \mathrm{mM}$ each), $0.4 \mu \mathrm{L}$ forward primer $(10 \mu \mathrm{M}), 0.4 \mu \mathrm{L}$ reverse primer $(10 \mu \mathrm{M}), 0.2 \mu \mathrm{L}$ Taq DNA polymerase $(5 \mathrm{U} / \mu \mathrm{L})$, and $5.2 \mu \mathrm{L} \mathrm{dd}_{2} \mathrm{O}$. The reactions were performed in accordance with the follows: $94^{\circ} \mathrm{C}$ for $5 \mathrm{~min}$, followed by 35 cycles of $94^{\circ} \mathrm{C}$ for $30 \mathrm{~s}, 56^{\circ} \mathrm{C}$ for $30 \mathrm{~s}$ and $72^{\circ} \mathrm{C}$ for $45 \mathrm{~s}$; and then $72^{\circ} \mathrm{C}$ for $10 \mathrm{~min}$. The amplicons were separated by $8 \%$ polyacrylamide gel electrophoresis $(160 \mathrm{~V}$ for $1.2 \mathrm{~h})$, and the gel was stained with silver nitrate.

For each marker, individuals consistent with the 18Q2513 (lobed-leaf) allele, the 18Q2515 (unlobed-leaf) allele, and the $F_{1}$ allele were categorized as 'a, 'b', and ' $h$ ', respectively. Genetic distances between markers were calculated by the Kosambi map function [38], and a genetic map was constructed using MapDraw [39].

\section{Candidate gene analysis}

To identify the lobed-leaf gene BoLl-1, genes located within the candidate interval were analyzed based on annotations for the B. oleracea 'TO1000' reference genome (http://plants.ensembl.org/Brassica_oleracea/ Info/Index) [18]. The expression patterns of candidate genes Bo9g181710 and Bo9g181720 were investigated using quantitative real-time PCR (qRT-PCR). Total RNA was extracted from 28-day-old seedling young leaves of the parents using TRIzol reagent (Invitrogen, United States) according to the manufacturer's protocol, and PrimeScript $^{\mathrm{TM}}$ RT Reagent Kit (Takara, Japan) was used to reverse transcribe cDNA from the total RNA extracted. qRT-PCR was carried out using a CFX96 Real-Time System (Bio-Rad) with SYBR Premix Ex TaqII Reagent Kit (Takara, Japan). Three biological and three technical replicates were included for each experiment. The relative expression level of each gene was calculated using the $2^{-\Delta \Delta \mathrm{Ct}}$ method [40]. The qRT-PCR primers used are listed in Table S2, and B. oleracea actin was employed as a control.

Gene-specific markers GL10 (primers GL10-F and GL10-R) and GL20 (primers GL20-F and GL20-R) (Table S2) were used to amplify the promoter and genomic sequences of $B o 9 g 181710$ and $B o 9 g 181720$, respectively. The resulting PCR products were analyzed by electrophoresis on $1 \%$ agarose gels, followed by sequencing and alignment. The co-dominant marker CMLMI1 (primers
CMLMI1-F1, CMLMI1-F2 and CMLMI1-R) and the derived cleaved amplified polymorphic sequence (dCAPS) marker DMLMI1 (primers DMLMI1-F and DMLMI1-R) (Table S2) were used to detect variations in the promoter of BoLMI1a in 118 different cabbage and ornamental kale inbred lines.

BLASTP searches were conducted using the amino acid sequence of BoLMI1a to search for homologues within the protein database of the National Center for Biotechnology Information (NCBI) and the B. oleracea reference genome 'TO1000'. Protein sequence alignment was performed with MAFFT (v7.037) [41]. FastTree (LG + JTT model) was used to construct phylogenetic trees [42].

\section{Abbreviations}

BC: Backcross; SNP: Single Nucleotide Polymorphism; LMI1: LATE MERISTEM IDENTITY 1; QTL: Quantitative Trait Locus; InDel: Insertion/Deletion; BSA: Bulk Segregant Analysis; dCAPS: Derived Cleaved Amplified Polymorphic Sequences; NCBI: National Center for Biotechnology Information.

\section{Supplementary Information}

The online version contains supplementary material available at https://doi. org/10.1186/s12870-021-03223-y.

Additional file 1: Table S1. Details of SNP and InDel variations in the candidate region of BOLI-1.

Additional file 2: Table S2. Primer sequences of the markers used in this study.

Additional file 3: Figure S1. Amplicons of the dCAPS marker DMLMI1 in parents and 118 different cabbage inbred lines and ornamental kale inbred lines 18Q2523. M represents the DNA ladder, $P_{1}$ is lobed-leaf inbred line $18 Q 2513$, and $P_{2}$ is unlobed-leaf inbred line $18 Q 2515$. Lane 1 is the ornamental kale inbred line 18Q2523 with lobed leaves, Lanes 2-119 are 118 different cabbage inbred lines with unlobed leaves.

Additional file 4: Figure S2. The original, full-length gel and blot images of Fig. 6. Figure S3. The original, full-length gel and blot images of Fig. S1.

\section{Acknowledgments}

Not applicable.

\section{Authors' contributions \\ Y. Zhang conceived and designed the experiments; B. Zhang, W. Chen and X Li performed the experiments and analyzed the data; B. Zhang and Y. Zhang wrote and revised the paper; and W. Ren, L. Chen, F. Han, Z. Fang, L. Yang, M. Zhuang, H. Lv, and Y. Wang coordinated and designed the study. All authors have read and approved the final manuscript.}

\section{Funding}

This work was supported by grants from the National Natural Science Foundation of China (31872948). The work was performed in the Key Laboratory of Biology and Genetic Improvement of Horticultural Crops, Ministry of Agriculture, Beijing 100081, China. All funders were not involved in the design, data analysis, and writing of the study.

\section{Availability of data and materials}

All data generated or analyzed during this study are included in this published article and its supplementary information files. The raw sequencing data used during this study are available in the NCBI SRA database (Accession number: PRJNA729727, https://www.ncbi.nlm.nih.gov/sra/PRJNA729727). The 
B. oleracea reference genome 'TO1000' used in this study can be found at the link: http://plants.ensembl.org/Brassica_oleracea/Info/Index. The A. thaliana genome can be found at the link: https://www.arabidopsis.org/. The protein database of National Center for Biotechnology Information (NCBI) can be found at the link: https://www.ncbi.nlm.nih.gov/. All these databases are open to public access.

\section{Declarations}

\section{Ethics approval and consent to participate}

All the plant materials are from the Institute of Vegetables and Flowers, Chinese Academy of Agriculture Sciences (IVFCAAS, Beijing, China). The utilization of these plant materials in this study complies with the guidelines and legislation of China.

\section{Consent for publication}

Not applicable.

\section{Competing interests}

The authors declare that they have no competing interests.

Received: 10 May 2021 Accepted: 22 September 2021

Published online: 06 October 2021

\section{References}

1. Tsukaya H. Mechanism of leaf-shape development. Annu Rev Plant Biol. 2006;57:477-96.

2. Tsukaya H. Leaf shape: genetic controls and environmental factors. Int J Dev Biol. 2005;49:547-55.

3. Nikovics K, Blein T, Peaucelle A, Ishida T, Morin H, Aida M, et al. The balance between the MIR164A and CUC2 genes controls leaf margin serration in Arabidopsis. Plant Cell. 2006;18:2929-54.

4. Ren J, Liu Z, Du J, Fu W, Hou A, Feng H. Fine-mapping of a gene for the lobed leaf, BoLI, in ornamental kale (Brassica oleracea L. var. acephala). Mol Breed. 2019;39:40.

5. Pu HM, Fu SZ, Qi CK, Zhang JF, Wu YM, Gao JQ, et al. Inheritance of divided leaf trait of rapeseed (Brassica napus) and application in hybrid breeding. Chin J Oil Crop Sci. 2001;23:60-2.

6. Zhuang J, Zhou XR, Li SL, Gu LD. Breeding of divided leaf two-type line of recessive genic male sterility in Brassica napus L. Acta Agric Shanghai. 2003;19(2):17-9.

7. Vogel S. Leaves in the lowest and highest winds: temperature, force and shape. New Phytol. 2009;183:13-26.

8. Peppe DJ, Royer DL, Cariglino B, Oliver SY, Newman S, Leight E, et al. Sensitivity of leaf size and shape to climate: global patterns and paleoclimatic applications. New Phytol. 2011;190:724-39.

9. Tu YQ, Sun J, Dai XL, Tang J, Tu WF, Shao HQ. Character and genetic analysis of lobed-leaf traits in Brassica napus. Chin J Oil Crop Sci. 2013;35:93-6.

10. Schmidt S, Zietz M, Schreiner M, Rohn S, Kroh LW, Krumbein A. Genotypic and climatic influences on the concentration and composition of flavonoids in kale (Brassica oleracea var. sabellica). Food Chem. 2010;119:1293-9.

11. Song K, Slocum MK, Osborn TC. Molecular marker analysis of genes controlling morphological variation in Brassica rapa (syn. Campestris). Theor Appl Genet. 1995;90:1-10.

12. Kubo N, Saito M, Tsukazaki H, Kondo T, Matsumoto S, Hirai M. Detection of quantitative trait loci controlling morphological traits in Brassica rapa $\mathrm{L}$. Breed Sci. 2010;60:164-71.

13. Wang $Y$, Liu X, Ji X, Zhang L, Liu Y, Lv X, et al. Identification and validation of a major QTL controlling the presence/ absence of leaf lobes in Brassica rapa L. Euphytica. 2015;205:761-71.

14. Kawakatsu Y, Sakamoto T, Nakayama H, Kaminoyama K, Igarashi K, Yasugi $M$, et al. Combination of genetic analysis and ancient literature survey reveals the divergence of traditional Brassica rapa varieties from Kyoto, Japan. Hortic Res. 2021:8:132.

15. Ni X, Huang J, Ali B, Zhou W, Zhao J. Genetic analysis and fine mapping of the LOBED-LEAF 1 (BnLL 1) gene in rapeseed (Brassica napus L.). Euphytica. 2015;204:29-38.
16. Feng $X$, Li $X$, Yang $X$, Zhu P. Fine mapping and identification of the leaf shape gene BoFL in ornamental kale. Theor Appl Genet. 2020;133:1303-12.

17. Liu S, Liu Y, Yang X, Tong C, Edwards D, Parkin IA, et al. The Brassica oleracea genome reveals the asymmetrical evolution of polyploid genomes. Nat Commun. 2014:5:3930.

18. Parkin IA, Koh C, Tang H, Robinson SJ, Kagale S, Clarke WE, et al. Transcriptome and methylome profiling reveals relics of genome dominance in the mesopolyploid Brassica oleracea. Genome Biol. 2014;15(6):R77.

19. Michelmore RW, Paran I, Kesseli RV. Identification of markers linked to disease-resistance genes by bulked segregant analysis: a rapid method to detect markers in specific genomic regions by using segregating populations. Proc Natl Acad Sci U S A. 1991;88(21):9828-32.

20. Liu X, Yang C, Han F, Fang Z, Yang L, Zhuang M, et al. Genetics and fine mapping of a yellow-green leaf gene (ygl-1) in cabbage (Brassica oleracea var. capitata L.). Mol Breed. 2016;36:1-8.

21. Liu X, Gao B, Han F, Fang Z, Yang L, Zhuang M, et al. Genetics and fine mapping of a purple leaf gene, BoPr, in ornamental kale (Brassica oleracea L. var. acephala). BMC Genomics. 2017;18:230.

22. Lv H, Wang Q, Zhang Y, Yang L, Fang Z, Wang X, et al. Linkage map construction using InDel and SSR markers and QTL analysis of heading traits in cabbage. Mol Breed. 2014;34:87-98.

23. Han F, Yuan K, Kong C, Zhang X, Yang L, Zhuang M, et al. Fine mapping and candidate gene identification of the genic male-sterile gene $m s 3$ in cabbage 51S. Theor Appl Genet. 2018;131(12):2651-61.

24. Ji J, Yang L, Fang Z, Zhuang M, Zhang Y, Lv H, et al. Complementary transcriptome and proteome profiling in cabbage buds of a recessive male sterile mutant provides new insights into male reproductive development. J Proteome. 2018;179:80-91.

25. Zhang B, Han F, Cui H, Li X, Ren W, Fang Z, et al. Insertion of a CACTAlike transposable element disrupts the function of the BoCCD4 gene in yellow-petal Chinese kale. Mol Breed. 2019;39(9):130.

26. Zhu P, Feng X, Cheng M, Pan Z, University SA. Genetic analysis of feathered-leaved related traits in Brassica oleracea var. acephala. Acta Botan Boreali-Occident Sin. 2016:36(2):0288-95.

27. Hu L, Zhang H, Yang Q, Meng Q, Han S, Nwafor CC, et al. Promoter variations in a homeobox gene, BnA10.LMI1, determine lobed leaves in rapeseed (Brassica napus L.). Theor Appl Genet. 2018;131(12):2699-708.

28. Pettigrew WT, Heitholt JJ, Vaughn KC. Gas-exchange differences and comparative anatomy among cotton leaf-type isolines. Crop Sci. 1993;33:1295-9.

29. Chang L, Fang L, Zhu Y, Wu H, Zhang Z, Liu C, et al. Insights into interspecific hybridization events in allotetraploid cotton formation from characterization of a gene regulating leaf shape. Genetics. 2016;204:799-806.

30. Vuolo F, Mentink RA, Hajheidari M, Bailey CD, Filatov DA, Tsiantis M. Coupled enhancer and coding sequence evolution of a homeobox gene shaped leaf diversity. Genes Dev. 2016;30:2370-5.

31. Zhu QH, Zhang J, Liu D, Stiller W, Liu D, Zhang Z, et al. Integrated mapping and characterization of the gene underlying the okra leaf trait in Gossypium hirsutum L. J Exp Bot. 2016;67:763-74.

32. Andres RJ, Coneva V, Frank MH, Tuttle JR, Samayoa LF, Han SW, et al. Modifications to a LATE MERISTEM IDENTITY1 gene are responsible for the major leaf shapes of upland cotton (Gossypium hirsutum L.). Proc Natl Acad Sci U S A. 2017;114:E57-66.

33. Saddic LA, Huvermann B, Bezhani S, Su Y, Winter CM, Kwon CS, et al. The $\angle E A F Y$ target $L M I 1$ is a meristem identity regulator and acts together with $\angle E A F Y$ to regulate expression of CAULIFLOWER. Development. 2006;133:1673-82.

34. Sicard A, Thamm A, Marona C, Lee YW, Wahl V, Stinchcombe JR, et al. Repeated evolutionary changes of leaf morphology caused by mutations to a homeobox gene. Curr Biol. 2014;24:1880-6.

35. Vlad D, Kierzkowski D, Rast MI, Vuolo F, loio RD, Galinha C, et al. Leaf shape evolution through duplication, regulatory diversification, and loss of a homeobox gene. Science. 2014;343:780-3.

36. Song J, Li Z, Liu Z, Guo Y, Qiu LJ. Next-generation sequencing from bulked-segregant analysis accelerates the simultaneous identification of two qualitative genes in soybean. Front Plant Sci. 2017;8:919.

37. Murray MG, Thompson WF. Rapid isolation of high molecular weight plant DNA. Nucleic Acids Res. 1980;8:4321-5.

38. Kosambi $D$. The estimation of map distances from recombination values. Ann Eugenics. 1944;12:172-5. 
39. Liu R, Meng J. Map draw: a Microsoft excel macro for drawing genetic linkage maps based on given genetic linkage data. Hereditas. 2003;25(3):317-21.

40. Livak KJ, Schmittgen TD. Analysis of relative gene expression data using real-time quantitative PCR and the $2^{-\triangle \triangle C T}$ method. Methods. 2001;25:402-8,

41. Katoh K, Standley DM. MAFFT multiple sequence alignment software version 7: improvements in performance and usability. Mol Biol Evol. 2013;30:772-80.

42. Price MN, Dehal PS, Arkin AP. FastTree: computing large minimum evolution trees with profiles instead of a distance matrix. Mol Biol Evol. 2009;26:1641-50

\section{Publisher's Note}

Springer Nature remains neutral with regard to jurisdictional claims in published maps and institutional affiliations.

- fast, convenient online submission

- thorough peer review by experienced researchers in your field

- rapid publication on acceptance

- support for research data, including large and complex data types

- gold Open Access which fosters wider collaboration and increased citations

- maximum visibility for your research: over $100 \mathrm{M}$ website views per year

At BMC, research is always in progress.

Learn more biomedcentral.com/submissions 